\title{
Five year follow up of laser in situ keratomileusis for all levels of myopia
}

\author{
M O'Doherty, M O'Keeffe, C Kelleher
}

Br J Ophthalmol 2006;90:20-23. doi: 10.1136/bjo.2005.075127

Aims: To assess the long term refractive and visual outcome of patients who have laser in situ keratomileusis (LASIK) surgery.

Methods: This was a retrospective study of visual and refractive outcome of patients who had LASIK surgery performed in 1998 and 1999. All levels of myopia were included in the study. 49 patients attended for follow up. The main outcome measures were safety, predictability, efficacy, and stability. Postoperative complications and aberrations were also recorded. The mean preoperative spherical equivalent was -4.85 .

Results: At 2 months postoperatively $67 \%$ of eyes were within plus or minus $0.5 \mathrm{D}$ of attempted correction with $81 \%$ within plus or minus 1.0D. At 5 years postoperatively $60 \%$ of eyes were within plus or minus $0.5 \mathrm{D}$ of attempted correction with $83 \%$ within plus or minus $1.0 \mathrm{D}$. $88 \%$ of eyes had a vision of $6 / 12$ or better at 2 months compared to $89 \%$ of eyes at 5 years. Best spectacle corrected visual acuity (BSCVA) was unchanged or improved in $51 \%$. No eye lost more than one line of BSCVA. Overall, there was regression towards myopia with a mean change in refraction of $-0.5 \mathrm{D}$ over the 5 years. As expected, severely myopic patients regressed more with a mean change of $-1.06 \mathrm{D}$. However, there was a high level of patient satisfaction with the surgery. Conclusion: LASIK surgery offers predictable results in terms of refractive and visual outcome with mild regression in refraction over time.

$\mathrm{T}$ hough laser in situ keratomileusis (LASIK) surgery is now one of the most common operations performed worldwide, few studies have been published on long term outcome and safety. ${ }^{1-3}$

Photorefractive keratectomy (PRK) and LASIK have been shown to be comparable in terms of refractive outcome and visual performance for both myopic and hyperopic corrections. ${ }^{4-6}$ LASIK has become more popular because it is a pain free procedure and gives faster visual rehabilitation. However, LASIK is a more invasive procedure than PRK. LASIK surgery involves the formation of a flap at a level of $160 \mu \mathrm{m}$ from the corneal surface. This, theoretically, could disturb the organisation of collagen fibres that make up the corneal stroma at this level which could lead to compromise in corneal strength. Thus, there has been concern expressed over the long term refractive and biomechanical stability associated with LASIK surgery..$^{7-10}$

PRK has been shown to offer long term stability for up to 12 years. ${ }^{2}$ In contrast, the longest follow up of myopic LASIK has been 6 years and it showed modest results in terms of refractive, and visual outcome for high myopes. ${ }^{1}$ In this study we report the long term refractive stability for all levels of myopic correction and we review patient satisfaction with this procedure.

\section{PATIENTS AND METHODS}

This was a retrospective follow up study of visual and refractive outcome of patients who had LASIK surgery performed in 1998 and 1999. All levels of myopia were included in the study. There was a $98 \%$ compliance with follow up.

The main outcome measures were safety, efficacy, predictability and stability of refraction and vision over the 5 years.

Forty nine patients (90 eyes) attended for follow up, 53\% females and $47 \%$ males. The mean age was 39 years. Stratification of patients in terms of myopic level is shown in table 1. Patients were grouped into mild ( 0 to $-3.0 \mathrm{D})$, moderate $(-3.13$ to $-6.0 \mathrm{D})$, and severe (more than $-6.13 \mathrm{D}$ ) myopia. The preoperative and postoperative spherical equivalent for each group is shown in table 1 .

The initial surgery was performed by one experienced surgeon in the same clinic. The same surgeon saw all patients at follow up. The flaps were cut with a hansatome (Bausch and Lomb). Laser ablation was done with a $193 \mathrm{~nm}$ argon fluoride excimer laser (Bausch and Lomb 217 Technolas).

All patients had a detailed preoperative examination including unaided visual acuity (UAVA), BSCVA, refraction, slit lamp examination, pachymetry, and fundal examination. Patients were seen at 1 day, 1 week, 2 months, 6 months, 1 year, and at 5 years. The mean length of follow up was 62 months with a range of 57-72 months. Patients received a questionnaire at their last follow up visit to assess their satisfaction with the procedure.

Statistical analysis used in the study included a regression analysis to assess if there was a relation between various preoperative patient characteristics and their postoperative aberration profile.

\section{RESULTS}

\section{Predictability}

The percentage of eyes within plus or minus $0.5 \mathrm{D}$ and plus or minus 1.0D of the intended correction at 6 months and 60 months is shown in table 2 .

\section{Stability}

The mean change in refraction with time for patients with mild, moderate, and severe myopia is shown in figures $1-4$. In all cases, there was myopic regression $(-0.5 \mathrm{D})$, which was most aggressive in the severe myopes $(-1.06 \mathrm{D})$ and continued up to the 5 year follow up date. The mild myopes regressed in the first year and stabilised thereafter.

Abbreviations: BSCVA, best spectacle corrected visual acuity; LASIK, laser in situ keratomileusis; PRK, photorefractive keratectomy; SE, spherical equivalent; UAVA, unaided visual acuity 
Table 1 Stratification of all eyes into mild, moderate, and severe myopia

\begin{tabular}{|c|c|c|c|c|}
\hline & No of eyes & Preop SE & SE at 2 months & SE at 5 years \\
\hline Mild (0 to $-3.0 \mathrm{D})$ & 23 & & & \\
\hline Mean & & -2.42 & -0.15 & -0.4 \\
\hline SD & & 0.45 & 0.33 & 0.42 \\
\hline Range & & -3 to -1.5 & -0.75 to 0.5 & -1.25 to 0.5 \\
\hline Moderate $(-3.12$ to -6$)$ & 49 & & & \\
\hline Mean & & -4.45 & -0.17 & -0.4 \\
\hline SD & & 0.84 & 0.61 & 0.56 \\
\hline Range & & -6 to -3.13 & -1.5 to 1.25 & -1.0 to 1.0 \\
\hline Severe $(>-6.12)$ & 22 & & & \\
\hline Mean & & -8.29 & -0.98 & -1.05 \\
\hline SD & & 1.84 & 1.02 & 1.02 \\
\hline Range & & -13 to -6.0 & -3 to 0.75 & -3.25 to 0.5 \\
\hline All levels & 94 & & & \\
\hline Mean & & -4.85 & -0.36 & -0.54 \\
\hline SD & & 2.35 & 0.76 & 0.7 \\
\hline Range & & -13 to -1.5 & -3 to 1.25 & -3.25 to 1.0 \\
\hline
\end{tabular}

Mean SE (spherical equivalent) preoperatively and at all recorded time frames postoperatively.

Table 2 Percentage of patients within plus or minus $0.5 \mathrm{D}$ and plus or minus $1.0 \mathrm{D}$ of intended correction

\begin{tabular}{|c|c|c|c|c|}
\hline & $\begin{array}{l}\text { Within plus or minus } \\
0.5 \mathrm{D} \text { at } 6 \text { months }\end{array}$ & $\begin{array}{l}\text { Within plus or minus } \\
0.5 \mathrm{D} \text { at } 5 \text { years }\end{array}$ & $\begin{array}{l}\text { Within plus or minus } \\
1.0 \mathrm{D} \text { at } 6 \text { months }\end{array}$ & $\begin{array}{l}\text { Within plus or minus } \\
1.0 \mathrm{D} \text { at } 5 \text { years }\end{array}$ \\
\hline All levels & $72 \%$ & $60 \%$ & $89 \%$ & $83 \%$ \\
\hline Mild & $90 \%$ & $70 \%$ & $100 \%$ & $96 \%$ \\
\hline Moderate & $80 \%$ & $66 \%$ & $96 \%$ & $91 \%$ \\
\hline Severe & $33 \%$ & $33 \%$ & $61 \%$ & $50 \%$ \\
\hline
\end{tabular}

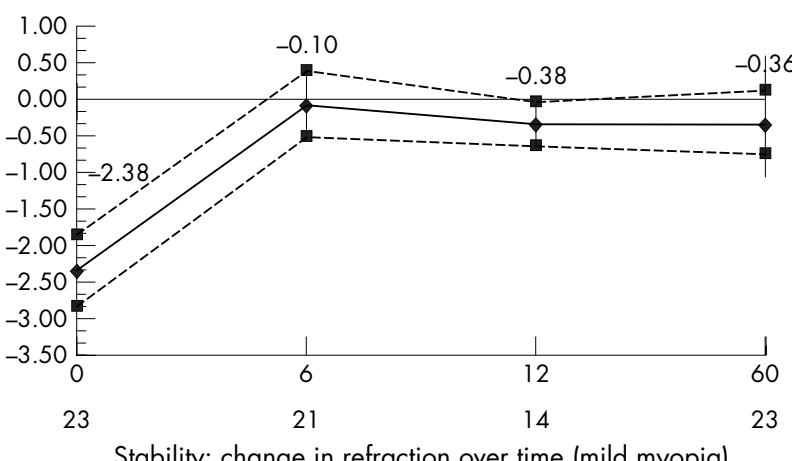

Stability: change in refraction over time (mild myopia)

Figure 1 Stability: change in refraction over time (mild myopia).

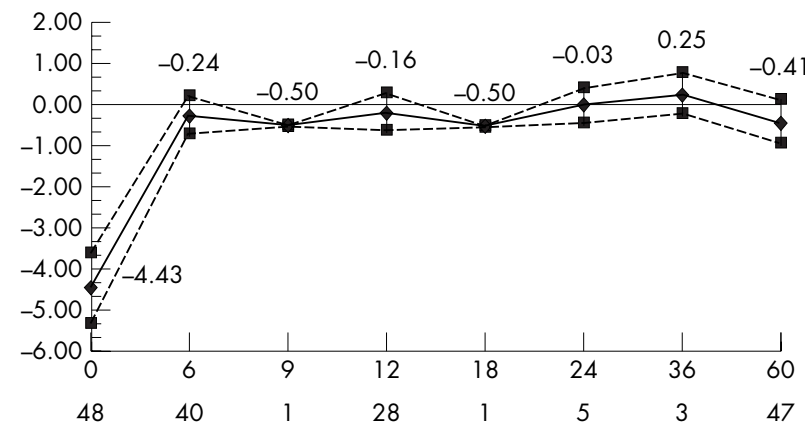

Stability: change in refraction over time (moderate myopia)

Figure 2 Stability: change in refraction over time (moderate myopia).

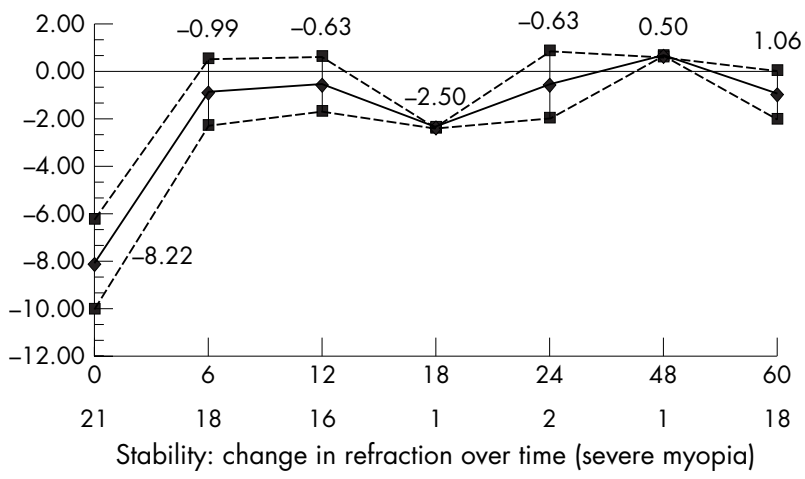

Figure 3 Stability: change in refraction over time (severe myopia).

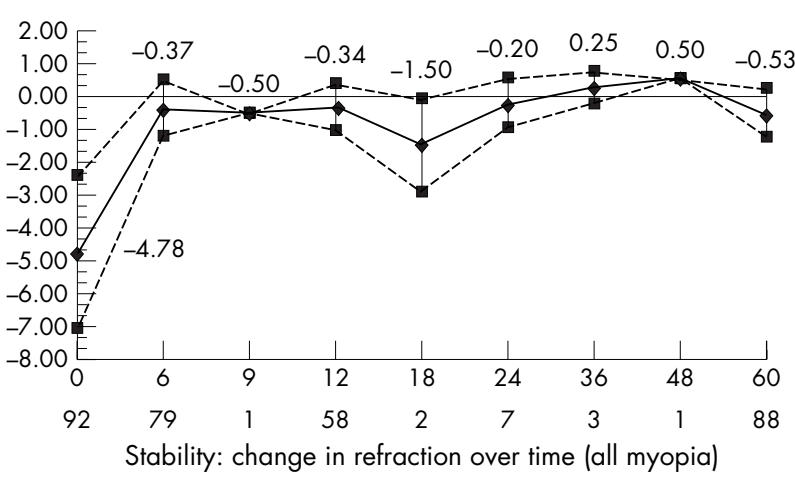

Figure 4 Stability: change in refraction over time (all levels myopia). 


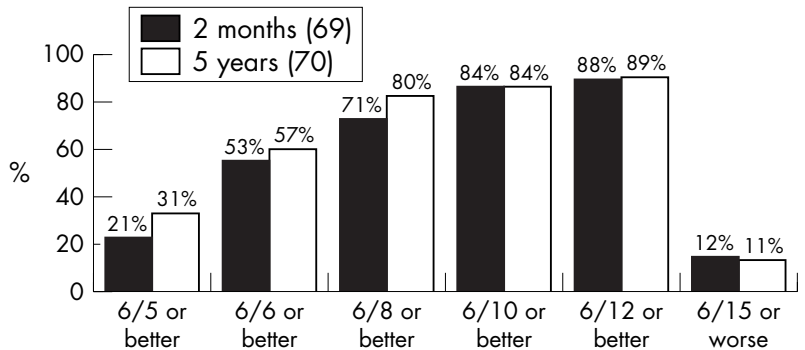

Figure 5 Efficacy: cumulative UCVA at 2 months and 5 years (all eyes).

\section{Efficacy}

Fifty seven per cent of all patients had an unaided visual acuity of $6 / 6$ or better at 5 years and $89 \%$ had a UCVA of $6 / 12$ or better. Ninety one per cent of mild myopes, $93 \%$ of moderate myopes, and $72 \%$ of severe myopes achieved a UCVA of $6 / 12$ or better. Cumulative UCVA is shown in figures 5 and 6.

\section{Safety}

BSCVA was unchanged or improved in $51 \%$. Forty six eyes were unchanged, 31 eyes gained one line, six eyes gained two lines, and one eye gained more than two lines. Six eyes lost one line and no eye lost more than one line of best corrected vision.

\section{Complication rate}

Twenty four per cent of patients reported glare and night vision problems postoperatively. One of these patients declined surgery on the other eye for fear of increasing the glare severity.

Four per cent of eyes had debris under flap requiring a relift and $2 \%$ had striae of the flap. Two per cent of eyes sustained a corneal abrasion at time of surgery and 3\% of patients reported haloes. At 5 years four eyes had been retreated for regression $(4.25 \%)$. Three of these eyes were severe myopes, giving a re-treatment rate of $13.6 \%$ among this group. One eye was re-treated within the moderate myopic group (re-treatment rate of $0.02 \%$ ) and no eye was retreated in the mild myopic group.

\section{Aberration profile}

All patients had an aberration scan at their 5 year visit. We did not perform aberrometry preoperatively. At the final visit the mean value for spherical and coma aberrations for all patients was -0.47 and 0.36 RMS. The mean optical zone treated was 5.79 and the mean scotopic pupil size was $5.6 \mathrm{~mm}$. We performed a regression analysis to calculate if the variables optical zone, pupil size, age, and spherical equivalent had any relation to those patients who reported glare symptoms. We found that age was the only significant

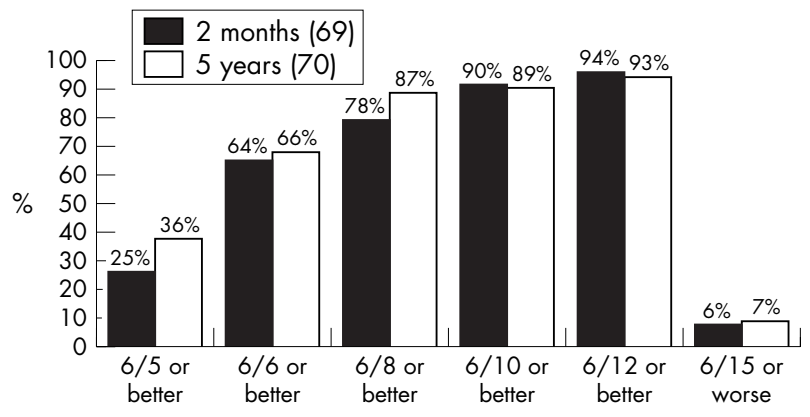

Figure 6 Efficacy: cumulative UCVA at 2 months and 5 years (mild/ moderate myopia). factor influencing whether patients reported glare as present or absent $(\mathrm{p}<0.05)$.

\section{Questionnaire}

There was a $100 \%$ response rate to the questionnaire. Ninety six per cent of patients surveyed would have LASIK surgery again and $92 \%$ of patients thought that the surgery changed their life significantly. Ninety six per cent of patients are currently happy with the quality of their vision and $100 \%$ of patients would recommend the surgery to a friend. Ninety eight per cent of patients reported that they were satisfied with the standard of care after treatment and $98 \%$ thought it was worth the price. We found that the most common reason for having the surgery was convenience.

\section{DISCUSSION}

LASIK surgery is still a controversial issue despite almost 10 years of experience and eight million patients treated worldwide. The recent publication by the National Institute of Clinical Excellence (NICE) in the United Kingdom, although fundamentally flawed, highlighted the need for long term evaluation of the procedure. Several studies have published good short term results for LASIK surgery; however, few have addressed long term outcome. ${ }^{1-3}{ }^{11-14}$

Sekundo et al, in a study of 33 eyes with 6 years of follow up, reported a cumulative unaided visual acuity of more than $0.4 \log$ MAR in $66 \%$ of patients and only $46 \%$ of patients were within plus or minus 1.0D of attempted correction at the end of the study. Furthermore, they reported that $75 \%$ of their patients experienced night-time glare, yet $81 \%$ of patients were quite happy with overall result. ${ }^{1}$

The long term results for PRK showed that postoperative refraction remained stable over 12 years. In 68 patients studied, it was found that $75 \%$ of those who underwent a $-2.0 \mathrm{D}$ correction and $65 \%$ of patients who received a $-3.0 \mathrm{D}$ correction were within $1 \mathrm{D}$ of intended correction at 12 years. This fell to $25 \%$ and $22 \%$ for patients having a $-6.0 \mathrm{D}$ and $-7.0 \mathrm{D}$ correction, respectively. ${ }^{2}$

The 5 year results for hyperopic LASIK were recently reported by Jaycock et al. ${ }^{3}$ They reported that at 5 years posttreatment $71 \%$ of eyes treated for +1.0 to $+3.0 \mathrm{D}$ of hyperopia were within plus or minus 1.0D of intended correction, whereas only $37.5 \%$ of those between $+3.5 \mathrm{D}$ and $+6.0 \mathrm{D}$ were within plus or minus 1.0D of intended correction.

In contrast with Sekundo's study where the mean preoperative SE was $-11.4 \mathrm{D}$, the patients in our study had a broader range of preoperative refraction (mean $\mathrm{SE}=-4.83$, range $=-1.5$ to $-13 \mathrm{D}$ ). Sixty per cent of eyes were within plus or minus $0.5 \mathrm{D}$ and $83 \%$ within plus or minus $1.0 \mathrm{D}$ of attempted correction at 5 years. Furthermore, $89 \%$ of eyes had a cumulative unaided vision of $6 / 12$ or better with $57 \%$ having a visual acuity of $6 / 6$ or better. The superior results are no doubt because of the inclusion of mild myopes in the study population. But if we exclude the high myopes in the study the results are even better, with $93 \%$ having an unaided vision of $6 / 12$ or better. Our findings show that LASIK surgery is predictable for mild to moderate myopia; however, beyond $-6.0 \mathrm{D}$ its efficacy decreases with a trend towards myopia over 5 years (fig 3). However, though we see a myopic trend over 5 years it is notable that $96 \%$ of patients would have the surgery again and 96\% are currently happy with their level of vision.

Like many other studies glare is a common side effect. We were unable to assess changes in glare sensitivity as these measurements were not performed preoperatively. In contrast with Sekundo's study, which reported glare in $75 \%$ of patients only $24 \%$ of our patients reported haloes/glare. Contrast sensitivity was not recorded preoperatively in our patients therefore we were unable to compare the levels of 
contrast sensitivity preoperatively to those at 5 years Contrast sensitivity is important in the evaluation of patients post-LASIK as it has been found that contrast sensitivity can be poor in the presence of good Snellen acuity. ${ }^{15}$ However, the evidence so far seems to suggest that LASIK causes a temporary reduction in contrast sensitivity with gradual normalisation by at least 6 months. ${ }^{16}{ }^{17}$ The range of methods available for the measurement of contrast sensitivity and the difficulties producing ambient conditions suitable for accurate assessment often deters surgeons from performing this exam in routine practice. Furthermore, even a slight decrease in contrast sensitivity can be within the normal range of a healthy control population. ${ }^{18}$

Overall, there was a $5 \%$ re-treatment rate during the 5 years. These re-treatments were performed in the first 6 months after surgery. All three patients were high myopes with spherical equivalents of $-13 \mathrm{D},-8.5 \mathrm{D},-9.5 \mathrm{D}$, and $-6 \mathrm{D}$, respectively. Following re-treatment at 5 years two eyes have achieved their best corrected visual acuity, one eye is within one line of best corrected acuity, and one eye is within two lines of best corrected acuity.

No patient developed corneal ectasia and $6 \%$ of patients reported dry eyes with only $4 \%$ requiring tear substitutes at 5 years.

Importantly, the safety profile of LASIK in this study is excellent. No eye lost more than one line of best spectacle corrected vision and 31 eyes gained one line of vision.

In conclusion, the findings in this study are significant. It is the largest long term outcome study published to date showing good unaided visual results with excellent safety profile. Overall patient satisfaction with the procedure is high with $98 \%$ reporting that they would have the surgery again. The emergence of better laser nomograms, safer keratomes, larger optical zones, and improved understanding of aberrations and their significance will lead to improvements in patient outcome in the future.

\section{Authors' affiliations}

M O'Doherty, M O'Keeffe, C Kelleher, National University of Ireland Dublin, Mater Private Hospital, Eccles Street, Dublin 7, Republic of Ireland
Correspondence to: Professor Michael O'Keeffe, Mater Private Hospital, Eccles Street, Dublin 7, Republic of Ireland; mokeeffe@materprivate.ie

Accepted for publication 21 August 2005

\section{REFERENCES}

1 Sekundo W, Bonicke K, Mattausch P, et al. Six year follow-up of laser in situ keratomileusis for moderate and extreme myopia using a first generation excimer laser and keratome. J Cataract Refract Surg 2003;29:1152-8.

2 Rajan MS, Jaycock $P, O^{\prime} B$ rart $D$, et al. A long-term study of photorefractive keratectomy. 12 year follow-up. Ophthalmology 111:10:1813-24.

3 Jaycock P, O'Brart D, Rajan MS, et al. 5 year follow-up of LASIK for hyperopia. Ophthalmology 112:2:191-9.

4 El-Agha MS, Johnston EW, Bowman RW, et al. Excimer laser treatment of spherical hyperopia: PRK or LASIK? Trans Am Ophthalmol Soc 2000;98:59-60.

5 El-Agha MS, Johnston EW, Bowman RW, et al. Photerefractive keratectomy versus laser in situ keratomileusis for the treatment of spierical hyperopia. Eye Contact Lens 2003;29:31-7.

6 Lee JB, Kim JS, Choe C, et al. Comparison of two procedures: photorefractive keratectomy versus laser in situ keratomileusis for low to moderate myopia. Jpn J Ophthalmol 2001;45:487-91.

7 Binder PS. Ectasia after laser in situ keratomileusis. J Cataract Refract Surg 2003;29:2419-29.

8 Kohnen T. latrogenic keratectasia: current knowledge, current measurements. J Cataract Refract Surg 2002;28:2065-6.

9 Comaish IF, Lawless MA. Progressive post-LASIK keratectasia: biochemical instability or chronic disease process? J Cataract Refract Surg 2002;28:2206-13.

10 Randleman JB, Russell B, Ward MA, et al. Risk factors and prognosis for corneal ectasia after LASIK. Ophthalmology 2003;110:267-75.

11 Sugar A, Rapuano CJ, Culbertson WW, et al. Laser in situ keratomileusis for myopia and astigmatism: safety and efficacy: a report by the American Academy of Ophthalmology. Ophthalmology 2002;109:175-87.

12 Knorz MC, Wiesinger B, Liermann A, et al. Laser in situ keratomileusis for moderate and high myopia and myopic astigmatism. Ophthalmology 1998; 105:932-40.

13 Guell JL, Muller A. Laser in situ keratomileusis for myopia from -7 to -18 dioptres. J Refract Surg 1996;12:222-8.

14 Maldonado-Bas A, Onnis R. Results of laser in situ keratomileusis in different degrees of myopia. Ophthalmology 1998;105:606-11.

15 Perez-Santonja JJ, Sakla HF, Alio JL. Contrast sensitivity after laser in situ keratomileusis. J Cataract Refract Surg 1998;24:183-9.

16 Mutyala S, McDonald M, Scheinblum KA, et al. Contrast sensitivity evaluation after laser in situ keratomileusis. Ophthalmology 2000;107:1864-7.

17 Carr JD, Stulting RD, Sano Y, et al. Prospective comparison of single-zone and multi-zone laser in situ keratomileusis for the correction of low myopia. Ophthalmology 1998;105:1504-11.

18 Arend O, Remky A, Evans D, et al. Contrast sensitivity loss is coupled with capillary dropout in patients with diabetes. Invest Ophthalmol Vis Sci 1997;33:1819-24. 